\title{
Omurganın travmatik çıkıkları
}

\section{Traumatic dislocations of the spine}

\author{
Mehmet Nuri Erdem ${ }^{1}$, Mehmet Tezer ${ }^{2}$ \\ ${ }^{1}$ Işık Üniversitesi, Sağlık Hizmetleri Meslek Yüksek Okulu, Ameliyathane Hizmetleri Bölümü, İstanbul \\ ${ }^{2}$ Nişantaşı Ortopedi Grubu, Beşiktaş, İstanbul
}

\begin{abstract}
Spinal kolonun pür çıkıkları spinal travmalar içerisinde nispeten nadir görülen yaralanmalardır. Bunlar daha çok servikal kolonu ilgilendirir ve torakal veya lumbosakral omurgada çok daha nadir görülür. Bu makalede spinal kolonun çıkıkları dört ana başıı altında incelenmiştir: 1) Atlanto-oksipital çıkıklar hiperfleksiyon ve distraksiyon mekanizması ile oluşan ligamentöz yaralanmalardır. Temel tedavisi oksipitoservikal artrodezdir. 2) Atlantoaksiyel çıkıklar atlas ve aksis artiküler proçeslerin birbirinden ayrılması durumudur. İnstabilitesi olan olgularda atlanto-aksiyel füzyon ile tedavi esastır. 3) Servikal faset eklem çıkıkları unilateral veya bilateral olmalarına göre tedavi edilir. Cerrahi tedavi seçiminde eşlik eden disk patolojileri önemlidir. 4) Torakolomber bölgedeki faset eklem çıkıkları ise hemen her zaman cerrahi tedavi edilir. Özellikle bilateral çıkıklarda değişen derecelerde nörolojik defisit eşlik eder. Bu nedenle erken tanı ve tedavi önem taşır.
\end{abstract}

Anahtar sözcülkler: omurga; çıkık; kırıklar ve çıkıklar; akut
Pure dislocations of the spinal column are relatively rare injuries in spinal trauma. They are more common in the cervical column, and are much less common in the thoracic or lumbosacral spine. In this article, the dislocations of the spinal column were examined under four main headings: 1) Atlanto-occipital dislocations are ligamentous injuries caused by hyperflexion and distraction mechanism. The main treatment is occipitocervical arthrodesis. 2) Atlantoaxial dislocations are the separation of atlas and axis articular processes. Treatment with atlanto-axial fusion is essential in patients with instability. 3) Cervical facet joint dislocations are treated according to whether they are unilateral or bilateral. Accompanying disc pathologies are important in the choice of surgical treatment. 4) Facet dislocations in the thoracolumbar region are almost always treated surgically. In particular, bilateral dislocations are accompanied by varying degrees of neurological deficit. Therefore, early diagnosis and treatment is important.

Key words: spine; dislocation; fractures and dislocations; acute

\section{ATLANTO-OKSIPITAL ÇIKIKLAR}

Atlanto-oksipital çıkıklar nadir görülen, genellikle künt travma sırasında hiperfleksiyon ve distraksiyon mekanizması ile oluşan ligamentöz yaralanmalardır. Oksipital kondillerin daha düz olması ve bağ laksitesi nedeni ile çocuklarda daha sık görülür. ${ }^{[1]}$ Spinal kordun, beyin dokusunun ve kraniyal sinirlerin kompresyon, distraksiyon veya distorsiyon ile hasarı sonucu anlamlı düzeyde nörolojik defisit ile seyreden, oldukça instabil ve çoğunlukla ölümcül yaralanmalardır. Ayrıca eşlik eden serebrovasküler yaralanmalar mortalite ve morbiditeyi arttırır. Illk yardım tekniklerindeki gelişmeler ve hasta transferi sırasında omurganın uygun şekilde tespitinin yapılması sayesinde, çoğu hasta acil servise ulaşabilmektedir. Son yıllarda ilerleyen görüntüleme

yöntemleri ve girişim teknikleri sonucu, bu yaralanmalardan sonra hayatta kalma oranı da artmıştır. ${ }^{[2]}$ Temel yaralanma mekanizması başa göre gövdenin ani olarak yavaşlamasıdır. Kafatasını boyuna bağlayan tüm bağlar özellikle tektorial membran, alar bağlar ve kondil kapsüllerinin hepsi yaralanır. Direkt grafi ve bilgisayarIı tomografi (BT)'de atlanto-dental mesafe ölçülerek bağ yırtığına bağlı çıkık anlaşılır. Powers ve ark., atlanto-oksipital eklem çıkığı tanısı için bir oran ortaya koymuşlardır. ${ }^{[3]}$ Buna göre; lateral servikal radyografilerde basion ile atlasın posterior arkı arasındaki mesafenin opistion ile atlasın anterior arkı mesafeye oranı 1 'den büyükse tanıyı destekleyicidir (Şekil 1). ${ }^{[4]}$

Klinik olarak solunum durması ve tam kuadriplejiden tamamen normal nörolojik duruma kadar değişen

- İletişim adresi: Dr. Mehmet Nuri Erdem, Işık Üniversitesi, Sağlık Hizmetleri Meslek Yüksek Okulu, Ameliyathane Hizmetleri Bölümü, Büyükdere Cad. 34298, Maslak, İstanbul Tel: 0533 - 2215938 e-posta: mnerdem@yandex.com

- Geliș tarihi: 9 Kasım $2018 \quad$ Kabul tarihi: 9 Kasım 2018 


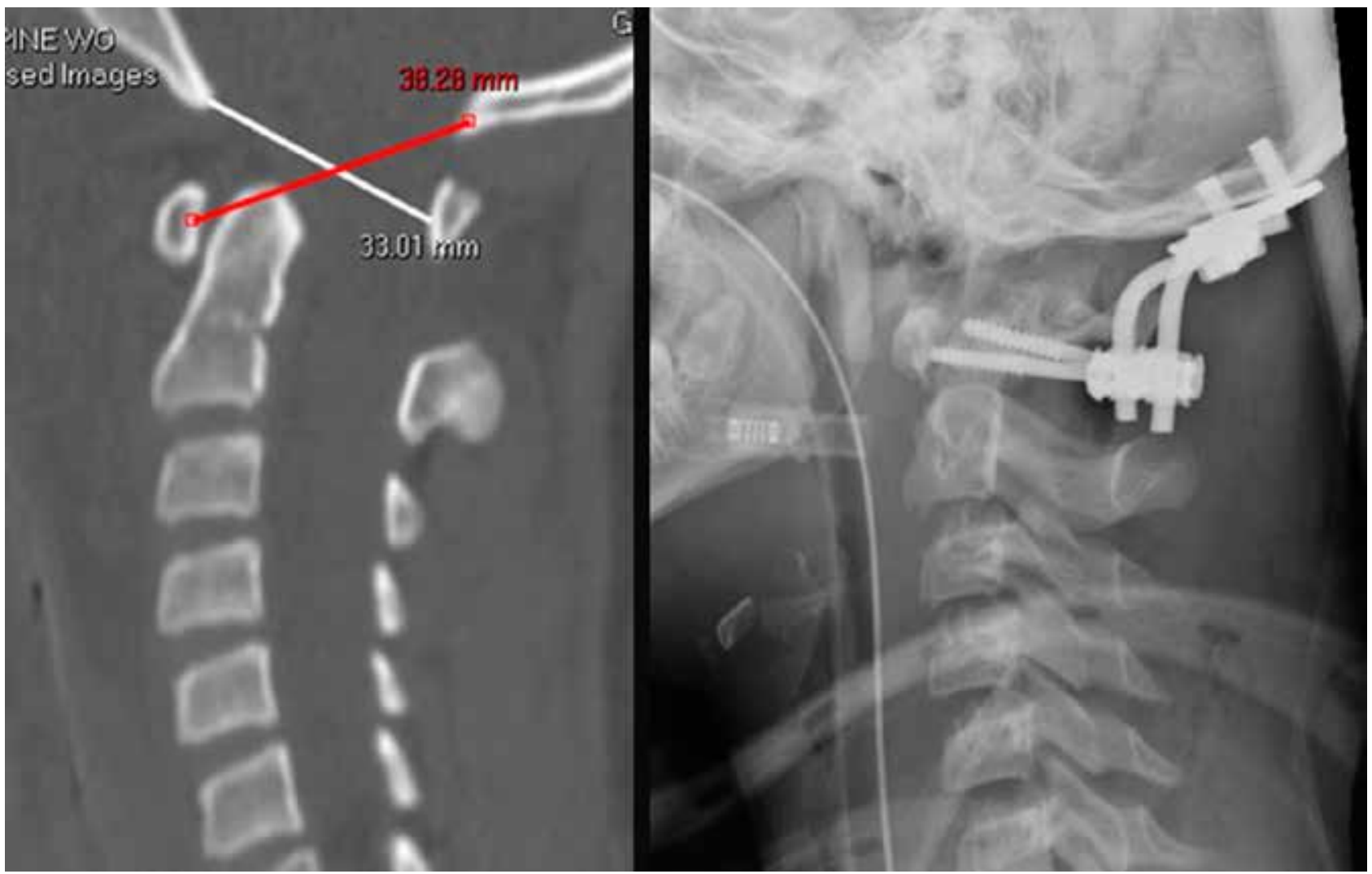

Şekil 1. Atlanto-oksipital çıkıkta sagittal BT görüntüsünde anormal Powers oranı (>1) görülmekte. Hastanın tedavisi oksipitoservikal plak ile füzyon uygulanarak yapılmıştır. ${ }^{[4]}$

yelpazede olabilir. Eşlik eden kraniyal sinir paralizilerine de rastlanabilir. Suboksipital bölgede lokalize hematom, atlanto-oksipital travmayı akla getirmelidir. Klinik bulgular arasında; alt düzey kraniyal sinirlere ait parezi, tek veya iki taraflı güçsüzlük, monoparezi, hemiparezi, kuadriparezi ve solunum fonksiyon bozukluğu vardır. Ancak, akut travmatik atlanto-oksipital eklem çıkığı olan hastaların \%20'sinde nörolojik bulgular geçici olup başvuru esnasında nörolojik tutulum olmadan şiddetli boyun ağrısı olabilir.

Atlanto-oksipital çıkıklar, Traynelis ve ark. ${ }^{[5]}$ tarafından dört tipe ayırılarak sınıflandırılmıştır:

Tip 1: Anterior; oksipital kemiğin atlasın anterioruna doğru yer değiştirmesi.

Tip 2: Longitudinal; oksipital kemiğin atlastan longitudinal distraksiyon ve separasyonu.

Tip 3: Posterior; oksipital kemiğin atlasın posterioruna doğru yer değiştirmesi.

Tip 4: Kompleks; lateral, rotasyonel ve çok yönlü çıkıklar.
Atlanto-oksipital eklem çıkığı tedavisinin amacı, stabilitenin sağlanıp nörolojik fonksiyonların korunmasıdır. Hastaların başlangıç tedavisinde traksiyon tartışmalıdır. Tip 2 olgularda esas problem longitudinal instabilite olduğundan, traksiyon kontrendikedir. Tip 1 ve Tip 3 çıkıklarda ise, çok düşük ağırlıkla anatomik dizilim sağlanmaya ve nöral yapılar dekomprese edilmeye çalışılır. Bu aşamada hastaların yakın klinik ve radyolojik takibi önemlidir. Bu yaralanmalarda ani savrulmaya bağı baş adeta boyundan ayrıldığı için hangi tip olursa olsun son derece instabil yaralanmalardır ve spontan iyileşme şansı yoktur. Bazı hastalar traksiyon ve uzun süreli immobilizasyon ile başarılı şekilde tedavi edilseler de başı boyuna bağlayan tüm bağ ve membranlar hasarlandığından instabilite devam eder. Rijid internal tespit ile yapılan oksipitoservikal artrodez en efektif ve kesin tedavi yöntemidir. ${ }^{[6]}$

\section{ATLANTO-AKSIYEL ÇIKIKLAR}

Atlas ve aksisin artiküler proçeslerinin birbirinden ayrılması ile sonuçlanan yaralanma durumudur. 
Atlanto-aksiyel rotatuvar subluksasyonlar olarak da anılır. Atlas ile aksis arasındaki eklemleşme spinal kolonun en hareketli ve doğal olarak stabilitesi en az olan bölgesidir. Üst servikal bölgenin en güçlü bağı transvers bağdır. Transvers bağın yaralanması bu çıkığın temelini oluşturur. Atlanto-aksiyel çıkık sıklıkla travma, romatoid artrit gibi inflamatuvar veya Down sendromu gibi konjenital hastalıklara bağlı gelişir. Fleksiyon, distraksiyon ve rotasyon bu çıkıklara neden olan yaralanma mekanizmalarıdır. ${ }^{[7]}$ En sık oluşum mekanizması başın oksipital bölgesinden anteriora doğru giden güçlerin etkisi ile oluşan zorlu fleksiyon yaralanmalarıdır. Transvers ve alar bağlar atlanto-aksiyel stabiliteden sorumludur ve eğer transvers bağ hasarı mevcut ise, atlasın arkusu öne doğru yer değiştirerek kanal çapını daraltır ve nörolojik hasar riskini arttırır. Bu tür lezyonlar instabildir.

Anterior, posterior ve rotatuvar olarak üç tipte sınıflandırılabilir. Anterior subluksasyon hiperfleksiyon mekanizması ile oluşur. Fasetlerin belirgin diastazı ve üst üste kilitlenmesi tarzında kendini gösterir. Posterior tip nadir olarak görülür. Rotatuvar luksasyon minör travmayı takiben de görülebilir. Atlas ve aksis normalde $35^{\circ}$ 'lik rotasyon yapabilir. Eğer bu rotasyon $40^{\circ}$ 'yi geçerse faset kilitlenmesi meydana gelir ve karakteristik 'cockrobin' baş pozisyonuna yol açar. Baş bir tarafa $20^{\circ}$ eğik, karşı tarafa $20^{\circ}$ rotasyonda ve hafif fleksiyondadır. Tortikollisin yanında boyun hareketlerinde de kısıtlılık olur. Transvers bağın sağlam olduğu olgularda dens bir eksen etrafında öne doğru herhangi bir yer değiştirme olmaksızın 35-40' lik rotasyona uğrar. Bu tablo en sık rastlanan pediatrik rotatuvar atlanto-aksiyel luksasyonları oluşturur. Genellikle traksiyon ile düzeltilebilir. ${ }^{[8]}$

Atlanto-aksiyel çıkıkların radyografik tanısı lateral servikal fleksiyon-ekstansiyon radyografilerinde anterior atlanto-dental mesafenin (atlasın anterior arkının posterior kenarı ile densin anterior kenarı arası) değerlendirilmesi ile konulabilir. Bu mesafenin $<3$ $\mathrm{mm}$ olduğu durumlarda transvers bağın korunduğu düşünülür. Bu mesafenin $3 \mathrm{~mm}$ 'den büyük ama 5 mm'den küçük olduğu durumlarda transvers bağın yaralandığı, $5 \mathrm{~mm}$ 'den büyük olduğu $10 \mathrm{~mm}$ 'den küçük olduğu durumlarda transvers ve alar bağın beraber yaralandığı, 10 mm'den büyük olduğunda ise atlanto-aksiyel stabiliteyi sağlayan tüm bağların yaralandığı düşünülür. Sagittal ve koronal reformatlı BT kesitlerinin atlanto-aksiyel çıkığı görüntülemede duyarlıı̆ı̆ çok yüksektir. Manyetik rezonans (MR) görüntüleme ile, bu çıkıklara eşlik edebilecek fokal hematom, vertebral arter yaralanmaları, kapsüler şişlik, transvers ve alar bağların hasarı ortaya konabilir. ${ }^{[9]}$
Tüm atlanto-aksiyel çıkıklar internal veya eksternal olarak immobilize edilmelidir. Kesin tedaviden önce, iskelet traksiyonu ile çıkık redükte edilmelidir. Nörolojik tutulumu olan veya bilateral anterior translasyonu 3 mm'nin üzerinde olan olgular instabil olarak kabul edilmelidir. Eğer instabilite enfeksiyon veya romatoid artrite bağlı ise halo ile immobilize edilebilir. Travmatik instabiliteler enstrümanlı veya enstrümansız posterior atlanto-aksiyel füzyon gerektirir. Bilateral posterior translasyon ve buna bağlı odontoid yetmezliği veya kırığı redükte edilmeli, füzyon uygulanmalıdır. Unilateral anterior ve posterior rotasyonel çıkıklar ise, transvers bağ sağlam olduğu takdirde redükte edilip servikal kolar veya halo ile immobilizasyon sağlanabilir. Eğer nörolojik tutulum, fraktür ve transvers bağ hasarı varsa, posterior enstrümanlı atlanto-aksiyel füzyon yapılmalıdır. ${ }^{[10]}$

\section{SERVIKAL FASET EKLEM ÇIKIKLARI}

Servikal omurga yaralanmalarının üçte ikisi subaksiyel servikal omurgada meydana gelir. Kırıklar en çok C6-C7 seviyelerinde, çıkılar ise en çok C5-C6 ve C6C7 seviyelerinde görülür. ${ }^{[11]}$ Faset eklem çıkıkları esas olarak fleksiyon-distraksiyon mekanizması ile oluşur. Distraksiyon öncelikli olarak posterior elemanları etkiler. Basit tek taraflı faset luksasyonu ile bilateral zedelenmiş faset arasında değişen spektrumda hasarlar gözlenebilir. Her olguda değişen derecelerde, sadece posterior ligamentöz yapılarda değil diskin posterior anulusunda da görülebilen kopmalar gözlenebilir. Unilateral faset çıkığı sık karşılaşılan bir servikal omurga yaralanması olup inferior fasetin, superior fasetin anterioruna ilerlediği tek taraflı bir çıkık olarak tanımlanır. Bu çıkık tipi, fleksiyon-rotasyon yaralanması mekanizması sonucu oluşur. Unilateral faset çıkığı en sık C5-C6 seviyesinde görülür. Bilateral faset çıkıkları fleksiyon-rotasyon tipi yaralanmalar olup Evre 3 distraksiyon-fleksiyon yaralanması olarak kabul edilir. Bu yaralanmalar sonucu bir vertebra, kaudaldeki vertebra üzerinde yaklaşı $\% 50$ anteriora yer değiştirir. Genellikle her iki faset eklem kapsülü, posterior longitudinal ve interspinöz bağlar, posterior anulus fibrozus ve vertebral arter yaralanabilir. Unilateral faset çıkılarında hastalar, tek başına kök yaralanma bulguları veya tam olmayan nörolojik tutulum bulguları ile başvurabilirler. Bu çıkıkların iskelet traksiyonu ile redüksiyonu güçtür ve hastaların \%50'sinde başarısız olur. Bilateral çıkılarda ise nörolojik defisit oranı daha yüksektir. Traksiyon ile redüksiyonu unilateral çıkıklara göre daha kolaydır, fakat daha instabil oldukları için uzun süreli iskelet veya halo traksiyon ile tedavi edilirse tekrar çıkık oluşma olasılığı daha yüksektir. ${ }^{[9]}$ 


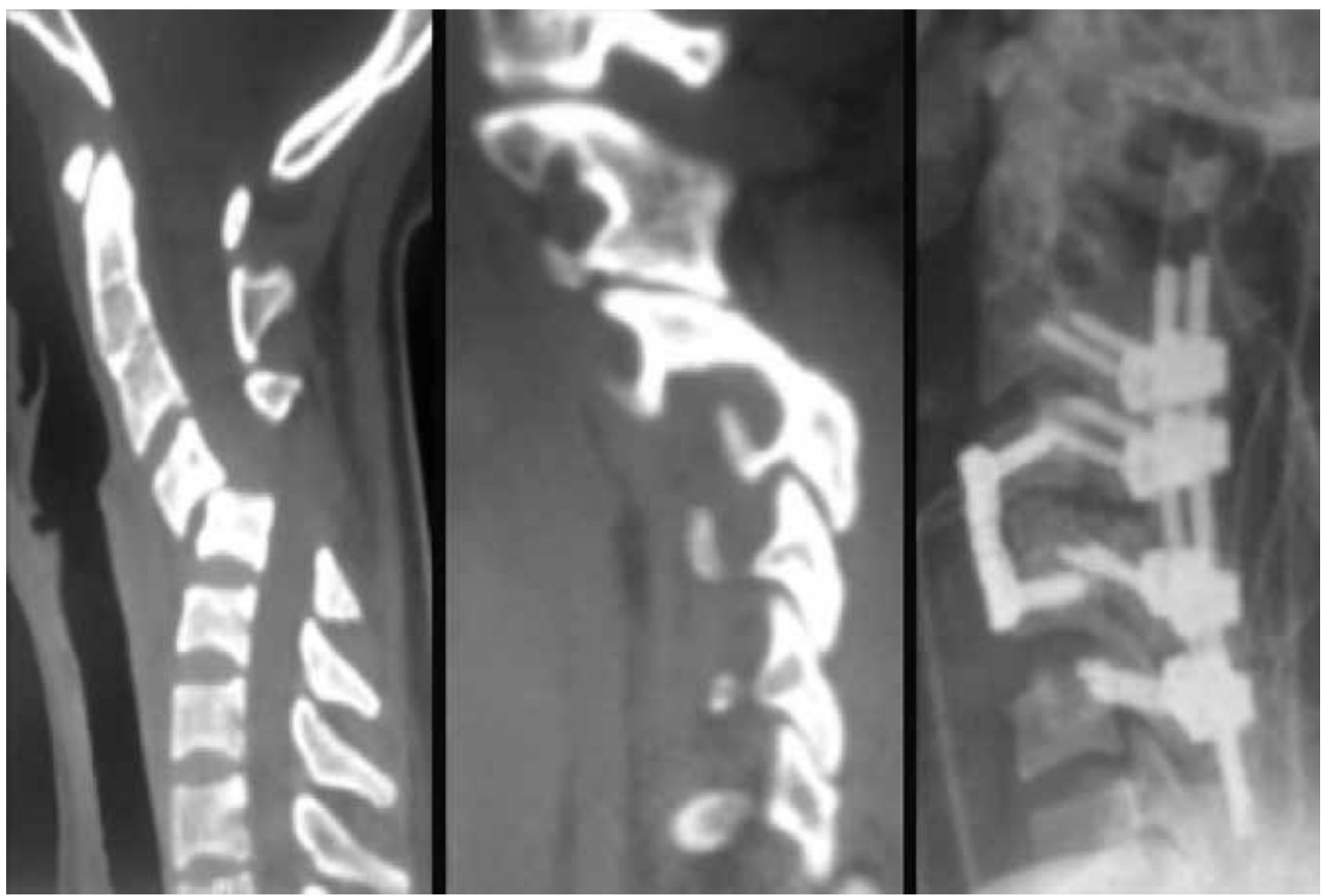

Şekil 2. Servikal omurganın BT incelemesinde C4-C5 seviyesinde bilateral faset eklemi çıkığına bağlı Grade 4 listezis görülmekte. C3-C6 arası lateral mass füzyon ve C4-C5 arası plak uygulanarak dizilim sağlanmış ve stabil füzyon elde edilmiş. ${ }^{[14]}$

Faset eklem çıkıklarının tanısı acil serviste grafiler ve BT ile konulur. Yumuşak dokuların hasarı ve yaralanmayla ilişkisinin incelenmesi açısından, MR efektif bir görüntüleme sistemidir. Yapılacak cerrahi stabilizasyondan önce kapalı redüksiyon ve traksiyon uygulamasının rolü tartışmalıdır. Güvenli bir redüksiyon işlemi, bilinci açık ve yapılacak seri nörolojik muayeneler esnasında koopere olabilecek hastalara yapılabilir. ${ }^{[12]}$ Kapalı redüksiyon yapılacak olsa da olmasa da hangi cerrahi yaklaşımın yapılacağı çeşitli faktörlere bağlıdır. MR'de posteriora herniye olmuş disk parçası mevcutsa tercih anterior yaklaşım olmalıdır. Disk-bağ kompleksindeki hasarın boyutu da seçilecek cerrahi yaklaşımın seçiminde önemlidir. Anterior diskektomi spinal kanalı direkt dekomprese edebilir ve takiben kapalı redüksiyon ile faset subluksasyonu düzeltilerek interbody greft ve anterior plak ile stabilizasyon yapılabilir. Bazı biyomekanik çalışmalar, bu yaralanmalarda anterior yaklaşımın posteriora göre zayıf olduğunu göstermiştir. ${ }^{[13]}$ Eğer sadece anterior yaklaşım planlanıyorsa yerleştirilecek intervertebral greftin faset eklemlere aşırı distraksiyon uygulamaması gerekir; eğer faset kırığı oluşursa, daha fazla fleksiyon distraksiyon yerine translasyon sonucu, kırık daha instabil hale gelebilir. Bu koşullar varlığında posterior stabilizasyon da düşünülmelidir (Şekil 2). ${ }^{[14]}$ Eğer disk herniyasyonu yoksa tek başına posterior stabilizasyon uygulanabilir. Eğer redüksiyon güç olursa, posterior translasyon öncesi bir miktar interlaminar distraksiyon ile kilitli fasetler açılabilir. Alternatif olarak, daha fazla doğrudan translasyona izin vermek ve aşırı distraksiyon gereksinimini azaltmak için kısmi fasetektomi uygulanabilir. Bu tekniğin dezavantajı, karşı fasete destek olacak kemik miktarında azalma sonucu redüksiyon sonrası stabilite kaybıdır. Kısmi faset rezeksiyonu, tipik olarak daha zorlu redüksiyona neden olan, geç başvuran çıkık olgularında gereklidir. Başarılı kapalı redüksiyon sonrası spinal kanal dekomprese olur ve spinal stabilizasyon daha sonra uygun bir zamanda planlanabilir. 


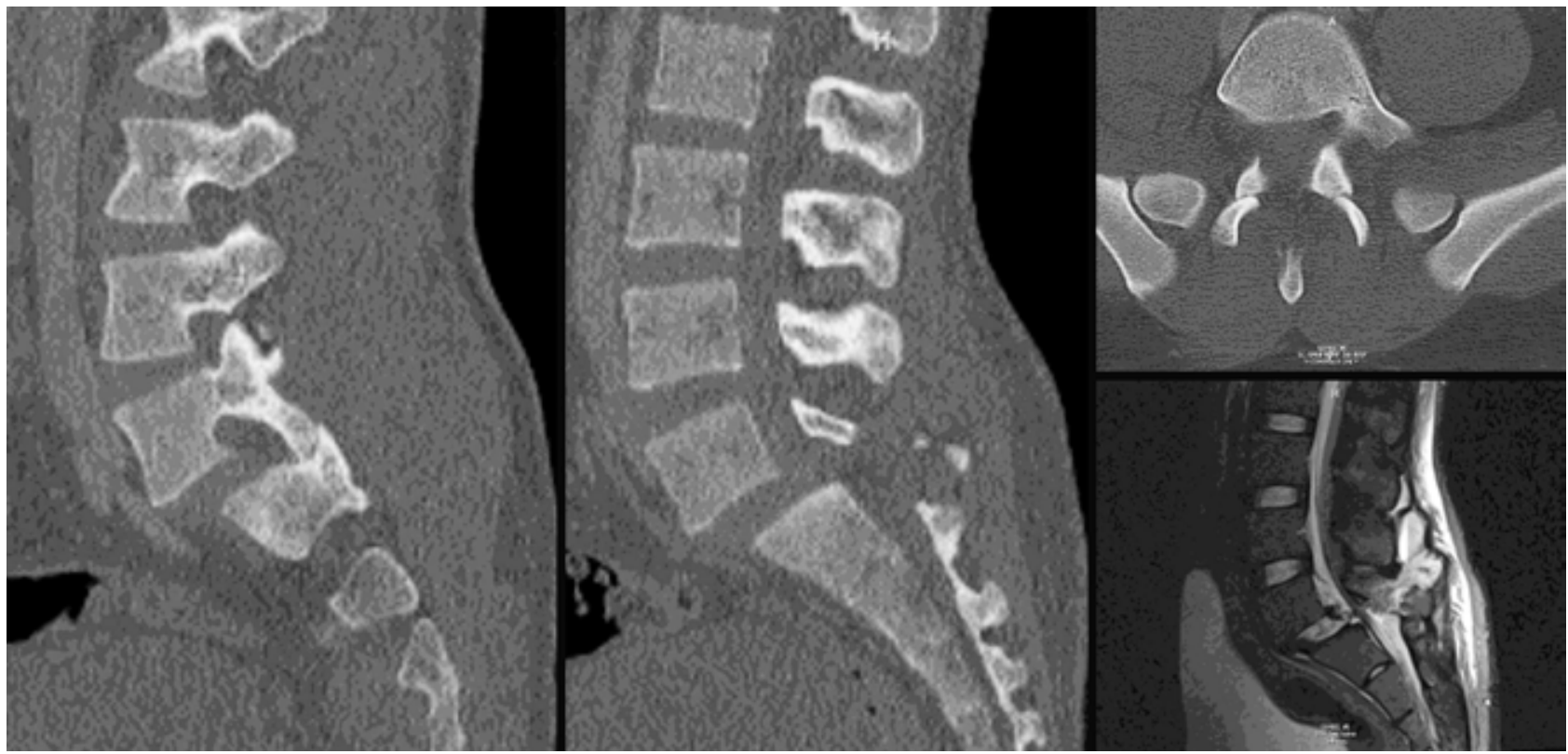

Şekil 3. Lumbosakral BT görüntülerinde L5-S1 seviyesinde kırık olmaksızın subluksasyon görülmekte. MR görüntüleri ise disk-bağ kompleksindeki hasarı göstermektedir. ${ }^{[18]}$

\section{TORAKOLUMBOSAKRAL FASET EKLEM ÇIKIKLARI}

Torasik ve lomber omurganın faset çıkıkları servikal bölgeye göre çok daha nadir oranda görülmektedir. Faset eklem çıkığının nedeni şiddetli fleksiyon-distraksiyon yaralanması sonucu posterior elemanların yetmezliğidir. Denis, bilateral faset çıkıklarında, posterior ligamentöz kompleksin (interspinöz bağ, faset eklem kapsülü ve ligamentum flavum) tek başına yaralanmasının fleksiyon instabilitesi oluşturmaya yetmeyeceğini, buna ek olarak posterior longitudinal bağ ve anulus fibrozusta da yaralanma olması gerektiğini vurgulamıştır. ${ }^{15]}$ Nörolojik hasar kanal içine yer değiştiren parçalar nedeniyle değil, nöral yapıların faset eklemler ile vertebra cisminin posterior-superior bölgesinin arasına sıkışması sonucu gerçekleşir. Bilateral faset eklem çıkıklarının \%75'inde nörolojik yaralanma komplet tiptedir. Tedavide bilateral faset eklem çıkıkları için açık redüksiyon ve posterior tespit önerilir. Torakal, torakolomber ve lomber omurgalarda faset eklem çıkıkları manipülasyon ile redükte edilemez. Anterior yaklaşım ise kontrendikedir, çünkü hasarlanmadan kalan tek bağın da ortadan kaldırılması sonucu instabilite gelişebilir. ${ }^{[9]}$

Lumbosakral faset dislokasyonlarını ilk kez WatsonJones ve Wilson, hiperekstansiyon yaralanması olarak tanımlamışlardır. ${ }^{[16]}$ Ancak günümüzde pek çok yazar, çıkığın çok yönlü yüklerin birleşimi sonucu oluştuğunu düşünmektedir. ${ }^{[17]}$ Travma mekanizmasına bağlı olarak değişen derecelerde disk-bağ kompleksi hasarları ortaya çıkar (Şekil 3). ${ }^{[18]}$ Lumbosakral çıkıklar parsiyel veya total çıkıklara neden olan unilateral veya bilateral faset eklem çıkıkları ile karakterizedir. Günümüzde kullanılan en yaygın sınıflama Vialle ve ark. tarafından tanımlanmıştır ${ }^{[19]}$ :

Tip 1: Kırık olmadan fasetlerin tek başına çıkığı.

1A: Unilateral rotasyonel çıkık.

1B: Lateral çıkık ve olası disk rüptürü ile beraber bilateral faset eklem çıkığı.

1C: Anterior yer değiştirme ile beraber bilateral çıkık.

Tip 2: Unilateral artiküler proçes kırı̆̆ına eşlik eden L5 vertebranın asimetrik anteriora yerdeğiştirmesi ve intervertebral disk yaralanması.

Tip 3: Bilateral kırıklı çıkığa eşlik eden spondilolistezis ve intervertebral disk yaralanması.

3A: Bilateral faset kırıklı çıkığı veya akut pars interartikülaris kırığı.

3B: Rotasyonel deplasman ile beraber bilateral faset kırı̆ına eşlik eden L5 vertebranın anteriora yer değiştirmesi. 
Travmatik lumbosakral çıkıklar sıklıkla eşlik eden başka yaralanmalar ile beraberdir. Devam eden bel ağrısı nedeni ile gecikmiş olarak tanısı konabilen pek çok olgu bildirilmiştir. ${ }^{[20]}$ Cerrahi tedavinin gecikmesi mevcut nörolojik hasarın ilerlemesi veya kalıcı hale gelmesi ile sonuçlanabilmektedir. ${ }^{[17]}$ Unilateral veya bilateral faset dislokasyonlarının tedavisi lumbosakral redüksiyon ve enstrümantasyon ile stabilizasyondur. Bu tedavi özellikle bilateral çıkıklarda önemlidir, çünkü bu yaralanmaların neredeyse üçte birine anlamlı nörolojik defisit eşlik eder.[21] Unilateral çıkıklarda ise nadiren nörolojik defisit oluşur. Radiküler defisitler fasetlerin deplasmanına bağlı kökün gerilmesi veya kompresyonu nedeni ile oluşur. En çok etkilenen, S1 sinir köküdür. Anterolistezisin redüksiyonu öncesi kanala migre olan olası disk parçalarının tespiti açısından ameliyat öncesi MR tetkiki yapılması önemlidir. L5 köklerinin eksplorasyonu ve foraminotomi ile görülmesi gerekir.

Akut dislokasyonlarda transpediküler vidalar ile distraksiyon yapılarak redüksiyon mümkündür. Ancak, aşırı distraksiyon gerektirebileceğinden, pür dislokasyon olgularında redüksiyonun temini için fasetektomi gerekebilir. Pedikül vidaları ile artrodez, primer tedavi metodudur. Disk hasarı olan olgular$\mathrm{da}$, tercihen posterior yolla interbody füzyon yapılarak vertebranın üç kolonunun birden stabilitesi sağlanabilmektedir. ${ }^{[22]}$

\section{KAYNAKLAR}

1. Garrett M, Consiglieri G, Kakarla UK, Chang SW, Dickman CA. Occipitoatlantal dislocation. Neurosurgery 2010;66(Suppl 3):A48-55. Crossref

2. Hadley MN, Walters BC, Grabb PA, Oyesiku NM, Przybylski GJ, Resnick DK, Ryken TC. Diagnosis and management of traumatic atlanto-occipital dislocation injuries. Neurosurgery 2002;50(Suppl 3):S105-13. Crossref

3. Powers B, Miller MD, Kramer RS, , Martinez S, Gehweiler JA. Traumatic anterior atlantooccipital dislocation. Neurosurgery 1979;4(1):12-7. Crossref

4. Kasliwal MK, Fontes RB, Traynelis VC. Occipitocervical dissociation -incidence, evaluation, and treatment. Curr Rev Musculoskelet Med 2016;9(3):247-254. Crossref

5. Traynelis VC, Marano GD, Dunker RO, Kaufman $\mathrm{HH}$. Traumatic atlanto-occipital dislocation. Case report. J Neurosurg 1986;65(6):863-70. Crossref

6. Lifeso RM, Colucci MA. Anterior fusion for rotationally unstable cervical spine fractures. Spine (Phila Pa 1976) 2000;25(16):2028-34. Crossref
7. Carroll EA, Gordon B, Sweeney CA, Joy S, Connolly PJ. Traumatic atlantoaxial distraction injury: a case report. Spine (Phila Pa 1976) 2001;26(4):454-7. Crossref

8. Hancı M, Erhan B. Omurga ve Omurilik Yaralanmaları. Bölüm 33 ve Üst servikal travmalarda tedavi algoritması. İzmir: Intertıp Kitapevi; 2013. s.296-7.

9. Okçu G, Erkan S, Akkaya G. Omurga çıkıkları. Turkiye Klinikleri J Orthop Traumatol-Special Topics 2011;4(3):38-45.

10. Tokuhashi $Y$, Matsuzaki H, Shirasaki $Y$, Tateishi T. C1-C2 intra-articular screw fixation for atlantoaxial posterior stabilization. Spine (Phila Pa 1976) 2000;25(3):337-41. Crossref

11. Goldberg W, Mueller C, Panacek E, Tigges S, Hoffman J, Mower W. Distribution and patterns of blunt traumatic cervical spine injury. Ann Emerg Med 2001;38(1):17-21. Crossref

12. Grant GA, Mirza SK, Chapman JR, Winn HR, Newell DW, Jones DT, Grady MS. Risk of early closed reduction in cervical spine subluxation injuries. J Neurosurg 1999:90(1):13-8. Crossref

13. Do Koh Y, Lim TH, Won You J, Eck J, An HS. A biomechanical comparison of modern anterior and posterior plate fixation of the cervical spine. Spine 2001;26(1):15-21. Crossref

14. Agrawal D, Singh PK, Mishra A. Delayed presentation of post-traumatic bilateral cervical facet dislocation: A series of 4 cases. Neurology India 2014;62(5):540. Crossref

15. Denis $F$. The three column spine and its significance in the classification of acute thoracolumbar spinal injuries. Spine (Phila Pa 1976) 1983;8(8):817-31. Crossref

16. Watson-Jones, R. Repair of Fractures. In: Wilson JN, editor. Fractures and Joint Injuries, Vol. 1. New York: Churchill Livingstone, Edinburgh; 1976. pp.11-50.

17. Daniels AH, Deodhar AA, Hart RA. Traumatic spondyloptosis resulting from high-energy trauma concurrent with a tonicclonic seizure. Spine J 2009;9(1):e1-4. Crossref

18. Xu R, Solakoglu C, Kretzer RM, McGirt MJ, Witham TF, Bydon A. Bilateral traumatic dislocation without fracture of the lumbosacral junction: case report and review of the literature. Spine (Phila Pa 1976) 2011;36(10):E662-8. Crossref

19. Vialle R, Charosky S, Rillardon L, Levassor N, Court C. Traumatic dislocation of the lumbosacral junction diagnosis, anatomical classification and surgical strategy. Injury 2007;38(2):169-81. Crossref

20. Szentirmai O, Seinfeld J, Beauchamp K, Patel V. Traumatic unilateral lumbosacral jumped facet without fracture in a child presentation of a safe treatment strategy for a rare injury. Patient Saf Surg 2008;2(1):29. Crossref

21. Hee HT, Thambiah J, Nather A, Wong HK. A case report of neurologically unstable fracture of the lumbosacral spine in a patient with ankylosing spondylitis. Ann Acad Med Singapore 2002;31(1):115-8.

22. Reddy SJ, Al-Holou WN, Leveque JC, La Marca F, Park P. Traumatic lateral spondylolisthesis of the lumbar spine with a unilateral locked facet: description of an unusual injury, probable mechanism, and management. J Neurosurg Spine 2008;9(6):576-80. Crossref 